Fourth International Conference on Sustainable Construction Materials and Technologies http://www.claisse.info/Proceedings.htm

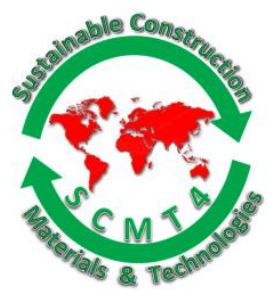

SCMT4

Las Vegas, USA, August 7-11, 2016

\title{
Condition Assessment and Finite Element Modelling of a Sulfur Pit Structure in the Sulfur Recovery Unit of a Gas Plant
}

\author{
M. K. Rahman ${ }^{1}$, H. A. Khalifah ${ }^{2 a}$, M. K. Ammar ${ }^{2 b}$, and E. Abu-Aisheh" \\ ${ }^{1}$ Research Institute, King Fahd University of Petroleum \& Minerals, Dhahran, Saudi Arabia, ${ }^{2}$ Consulting \\ Services Department, Saudi Aramco, Dhahran, Saudi Arabia;, 'Email: <mkrahman@kfupm.edu.sa>, \\ ${ }^{2 a}$ Email: <hasan.khalifa@aramco.com>, ${ }^{2 b}$ Email:<ammar.mohammed@aramco.com>, \\ ${ }^{2 c}$ Email:<emad.abuaisheh@aramco.com>.
}

\begin{abstract}
Sour crudes and gas with sulfur content more than $1.5 \%$ are encountered predominantly in the Saudi Arabian Oil/Gas fields. The molten sulfur compounds at temperatures ranging from $130{ }^{\circ} \mathrm{C}$ to $160{ }^{\circ} \mathrm{C}$, extracted from the hydrocarbons are stored in large subterranean reinforced concrete tank commonly referred to as sulfur pits. These sulfur pits have steam heaters at the base of the pits to maintain sulfur in liquid phase. The reinforced concrete sulfur pits exposed to a hostile, corrosive and hazardous environment suffer from extensive deterioration in a short span of time (less than 10 years). Corrosion of reinforcing steel, delamination and spalling of concrete cover occurs in the walls and the roof of the sulfur pit. Heavy deterioration is generally observed in the soffit of the roof slab with incidents of the roof collapsing. The sulfurous acid fumes, which are formed when the molten sulfur is exposed to water or steam, attack the reinforcing steel, causing corrosion. This paper presents a case study of the assessment of deteriorated sulfur pit based on non-destructive and partial destructive investigations and development of repair strategy to extend its service life.
\end{abstract}

\section{INTRODUCTION}

Sulfate attack on concrete is a complex form of deterioration that leads to damage in reinforced concrete structures. It is complex because of the various sources of sulfates attacking concrete (external source or internal delayed ettringite formation), and because the deterioration mechanism can be chemical in nature, due to, alteration of hydration of products, or physical, due to phase changes in the penetrating sulfate solution [Drimalas 2007]. A special type of structure exposed to high concentration of molten sulfur is the subterranean reinforced concrete tank, referred to as sulfur pit, which are built in oil/gas processing facilities to store molten sulfur. The molten sulfur compounds are stored at temperatures ranging from $130{ }^{\circ} \mathrm{C}$ to $160{ }^{\circ} \mathrm{C}$ in liquid phase, creating a highly corrosive and hazardous environment, which leads to extensive deterioration of concrete in a short span of time.

Although sulfate attack has been recognized as a cause of concrete distress for many years, it remains a controversial, confusing, and complex topic. Common forms of deterioration observed in the sulfur pits include corrosion of reinforcing steel and delamination and spalling of concrete cover in the walls and the 
roof of the sulfur pit. Heavy deterioration is generally observed in the soffit of the roof slab with incidents of the roof collapsing. The sulfurous acid fumes, which are formed when the molten sulfur is exposed to water leaking from external cracks or joints or steam leaking from steel coil, attack the reinforcing steel, causing corrosion.

This paper presents a case study of deterioration of an existing reinforced concrete sulfur pit exposed to high concentration of sulfate. The pit showed extensive cracking and delamination of concrete and partial collapse within a short span of time. A detailed field investigation of the pit was carried out involving visual inspection and laboratory studies on field concrete samples collected from the structure to investigate the sulfate attack on the concrete. 3D finite element modeling of the tank subjected to thermal stresses from the molten sulfur provided an insight into the accelerated deterioration of this sulfur pit.

\section{CONCRETE DETERIORATION MECHANISM IN SULFUR PITS}

External sulfate attack on reinforced concrete elements occurs when sulfate ions from an external source attacks the components of the cement paste. The attack occurs when concrete is in contact with sulfate containing environment. The chemical breakdown mechanism takes place due to interactions with calcium, sodium, and magnesium sulfate, which leads to the formation of gypsum and ettringite that cause concrete to crack and scale. Physical sulfate attack is one in which sulfates penetrate into concrete and lead to deterioration without chemically altering the hydration products within the concrete [Folliard and Sandberg 1994]. This distress, known as a physical sulfate attack, results from phase changes within the penetrating sulfate solution, which triggers crystallization pressures that can physically degrade concrete. Both laboratory studies and examinations of field concrete show that the external sulfate attack is often manifested, not by expansion or cracking, but by loss of cohesion and strength. [Drimalas 2007].

Moreover, sulfur indirectly leads to and accelerates the steel reinforcement corrosion in concrete. The presence of sulfur, moisture and oxygen in combination forms a very corrosive concentration of sulfuric acid. The sulfuric acid, consequently, reduces the concrete alkalinity, destroying the passivity protecting steel and causing corrosion. This explains the fact that most of the corrosion induced deterioration in the sulfur pits takes place on the walls levels above molten sulfur level and the roof. Although Type V cement is generally specified for use in concrete exposed to sulfate environment, it is considered less resistant to corrosion (less $\mathrm{C}_{3} \mathrm{~A}$ content) and therefore increases the potential of concrete deterioration due to reinforcement corrosion in sulfur pits.

The reinforced concrete structure storing the molten sulfur is subjected to extreme stresses due to temperature gradient across the concrete walls and the roof slab. The temperature gradient results in high tensile stress in these elements, resulting in the formation of micro and macro cracks. These cracks provide pathways and accelerates the ingress of sulfate ions, sulfuric acid and water from external sources (such as ground water, wash water and steam pipes ejecting water on top of roof), thereby causing deterioration of concrete and accelerating the reinforcement corrosion process. These thermal stresses in the concrete structure results in cracks exceed the allowable crack width of $0.1 \mathrm{~mm}$ as per ACI 201 guidelines [ACI 201.2R 2008]. Within a short span of time, less than 10 years, extensive cracking takes place in the walls and the roof slab of the sulfur pit. Extensive repair and rehabilitation work is required to restore the serviceability of these sulfur pits.

During embedded steel corrosion activities, the steel metallurgy changes, with corrosion products requiring and occupying more space than the parent material. As such, significant tensile stresses are exerted on the concrete in the immediate proximity of the corroding steel. As the concrete is weak in tension, unrestrained portions of the concrete mass (i.e. Protective cover over top of embedded reinforcing steel) will crack at the corroding rebar interface. Close examination of cracked concrete in the proximity of corroding reinforcement reveals radial cracking with corrosion products occupying the annular space of 
the crack fissure. The "wedging effect" of corrosion products along the planes of reinforcement form internal separations (i.e. delamination) within the mass that eventually leads to cross-section detachment of the concrete from the parent substrate (ie. spalling). Once this cover detaches, oxygen and moisture become abundantly available to fuel the corrosion process. The progression from crack-to-delaminationto-open spall accelerates the electrochemical processes of corrosion and can result in cases of diminished durability and structural integrity.

Another effect, reported by researchers in Canada [Dowling 1992], is the net corrosion reaction and formation of sulfur-deficient iron sulfide from the direct interaction of steel and solid elemental sulfur in the presence of moisture. Essentially, this type of corrosion is caused by the reduction of solid elemental sulfur in contact with exposed steel reinforcing bars and/or other steel embedment. This effect is becoming better understood when transporting solid elemental sulfur via bulk train cars and barge/shipping vessels with low moisture contents (1-2\% moisture by weight).

The external sulfate attack can be prevented through proper material selection and concrete mixture proportioning. There are several viable means of preventing sulfate attack, including reducing permeability and the use of lower w/cm, sulfate-resistant cements, and supplementary cementitious materials (SCMs). Significant correlation between higher permeability and greater expansion was reported with concretes exposed to 5\% sodium sulfate [Khatri, Sirivivatnanon and Yang 1997]. There have been only limited studies on methods of preventing physical sulfate attack. Folliard and Sandberg 1994 reported that low w/cm concrete mixtures are quite effective in preventing physical sulfate attacks, especially when SCMs are used. They also showed that air-entrainment is helpful in reducing but not eliminating physical sulfate attacks. With time, the air-entrained voids ultimately become filled with salts, and they are no longer accessible to the salt solution as it increases in volume.

\section{DESCRIPTION OF THE SULFUR PIT UNDER INVESTIGATION}

The sulfur pit under consideration is located within the Sulfur Recovery Unit at a Gas Plant in Saudi Arabia. The sulfur pit is $206.5 \mathrm{ft}(62.94 \mathrm{~m})$ long, $46 \mathrm{ft}(14 \mathrm{~m})$ wide and $7.7 \mathrm{ft}(2.34 \mathrm{~m})$ high. It is filled with molten sulfur compounds at temperatures ranging from 130 to $160{ }^{\circ} \mathrm{C}$ up to $5.5 \mathrm{ft}(1.67 \mathrm{~m})$ height. It was constructed in 1977 as a reinforced concrete tank with 3500 psi (24.1MPa) Type V Portland Cement Concrete proportioned to have reduced $\mathrm{C}_{3} \mathrm{~A}$. The minimum protective cover in the walls and the roof was 3 inches $(76.2 \mathrm{~mm})$. The roof slab of the sulfur pit is 15 inches $(381 \mathrm{~mm})$ thick, the base slab is 18 inches $(457 \mathrm{~mm})$ thick and the side walls of the tank is 15 inches $(381 \mathrm{~mm})$ in thicknesses. Concerns in the sulfur pit under study stems from the noticed sizeable cracking, exposed and corroding reinforcing steel bars at the base, and surface spalls and erosion on the roof slab and the interior wall surfaces. Several iterations of shotcrete restoration attempts were provided at the sulfur pit with little or no long-term success.

\section{FIELD AND LABORATORY INVESTIGATIONS OF THE SULFUR PIT}

All available project documents related to the construction of the sulfur pit (including previous inspections/maintenance reports) were studied. A detailed visual inspection of the sulfur pit roof, walls and slab surfaces was carried out. This was followed by investigations involving NDT and SDT, which included the acoustic impact testing concrete core and powder sampling, ground penetrating radar (GPR) testing, ultrasonic pulse velocity (UPV) testing as per ASTMC-597. Laboratory testing was performed on collected concrete samples, including chloride ion $\left(\mathrm{Cl}^{-}\right)$content, sulfate $\left(\mathrm{SO}^{--}\right)$content, depth of carbonation, and Portland cement content and compressive strength of concrete core specimens, as applicable. It should be noted that rebound hammer testing, impact-echo test testing and half-cell potential testing was not performed due to existing hazardous site conditions excluding their use. 


\section{Visual Inspection}

Visual Inspection of the accessible interior surfaces of the subsurface reinforced concrete sulfur pit was performed at the subject facility to document the observed deterioration in the form of cracks, delamination, spalls, erosion, and other significant features. Figure 1 shows typical view of the interior of the sulfur pit with sulfur adhered to the corners and edges of the roof from the sulfur fumes. The acoustic impact testing (i.e., mechanical hammer sounding) performed over the accessible and unobstructed concrete surfaces revealed localized areas of unsound and delaminated concrete throughout the sulfur pit with the major regions of delamination associated with the soffit of the roof slab and to a lesser degree on the interior vertical wall surfaces. Localized concrete delamination was generally observed on the top portions of the wall elements in the area of the "vapor zone" and the soffit of the roof slab of the sulfur pit as shown after removal in Figure 2.
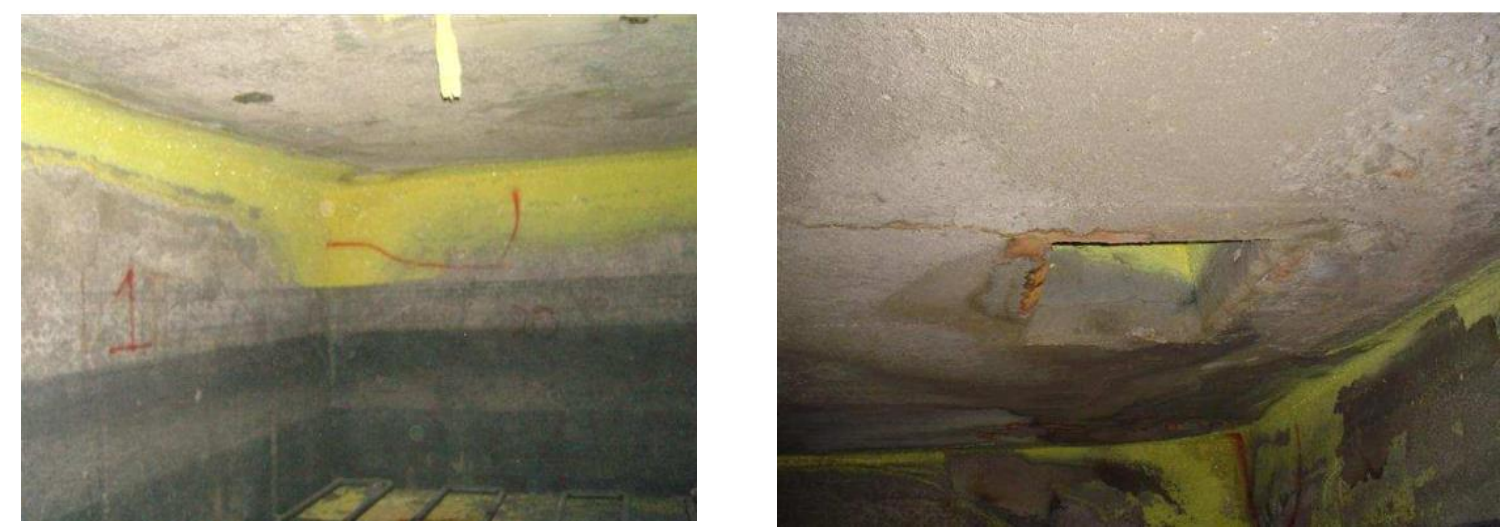

Figure 1. Typical view of the interior side of the sulfur pit

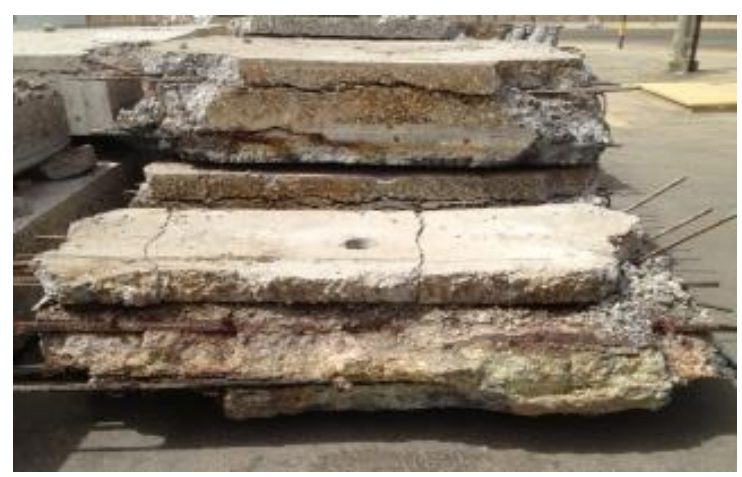

\section{Figure 2. Delamination in roof slab after removal from the sulfur pit during repair}

Distress in various concrete elements of the sulfur pit was schematically mapped and is presented in Figure 3 for the roof slab. It can be seen from the figure that the roof slab suffered from extensive deterioration. About $75 \%$ of the soffit of the roof slab showed delamination of the concrete cover. The soffit of the roof slab of the sulfur pit is the most conducive location for rapid deterioration of concrete and corrosion of reinforcing steel. It is subjected to sulfur fumes and the moisture and air is available abundantly, for rapid progression of the steel corrosion. Figure 4 shows areas of deterioration on the base slab. The 18 inch $(457 \mathrm{~mm})$ thick base slab, which is under the molten sulfur for most of the time, showed small areas of delamination and cracking at several locations together with spalling of concrete at a few locations. Figure 5 shows the crack mapping and deterioration on a typical wall. Interestingly, the top portion of the wall showed delamination, whereas, the portion under molten sulfur showed several horizontal and vertical cracks, with vertical cracks being predominant. 


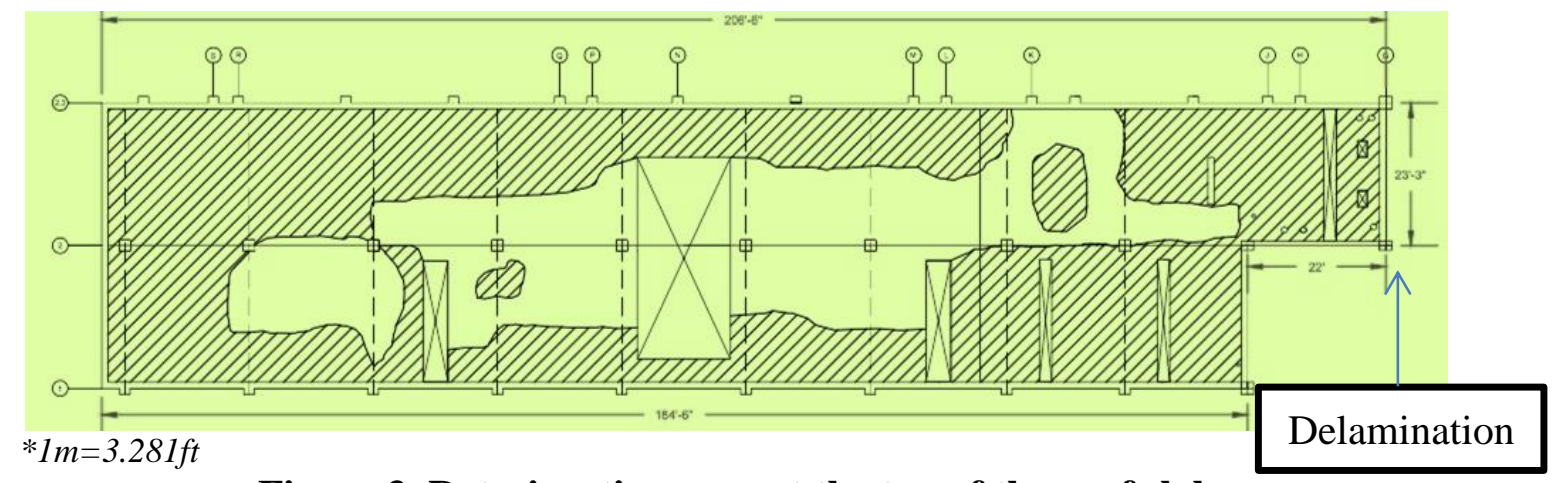

Figure 3. Deterioration map at the top of the roof slab

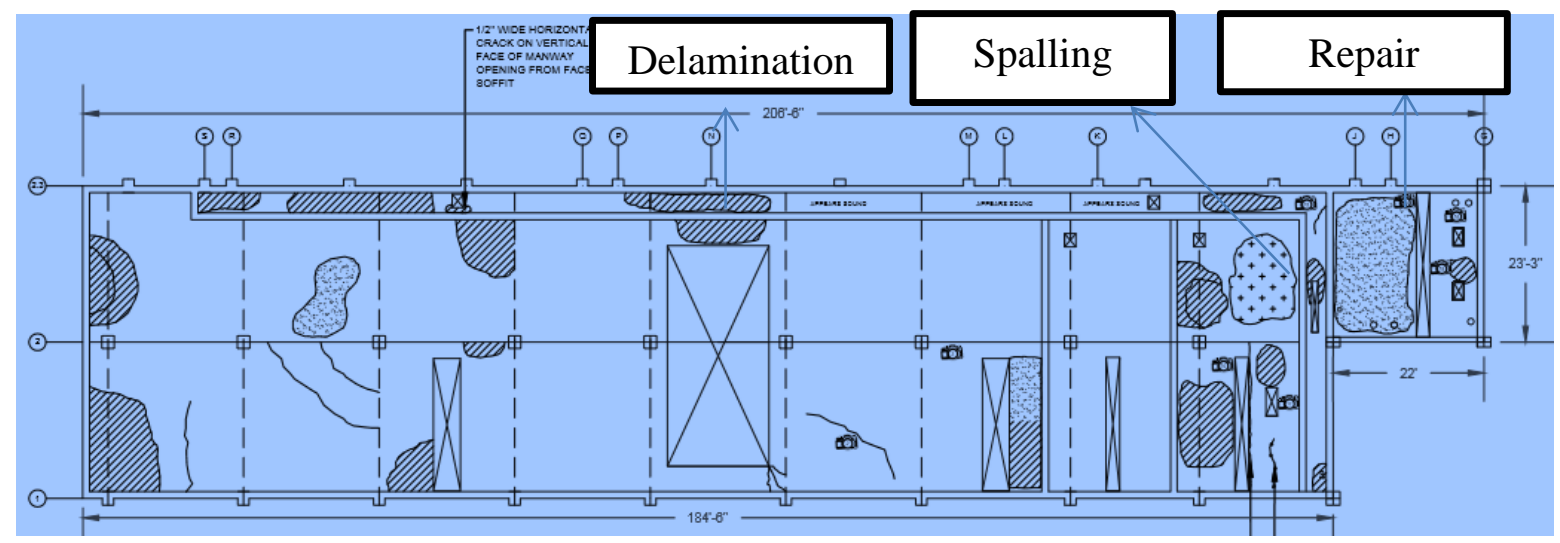

$* 1 m=3.281 \mathrm{ft}$

Figure 4: Deterioration map at the bottom of the roof slab

\section{Ultrasonic Pulse Velocity}

Ultrasonic pulse velocity (UPV) as per ASTM C-597 was conducted to determine the relative homogeneity of the concrete mass and subsurface anomalies (i.e., internal voids, cracks). UPV was carried out at 10 locations of the roof slab and the results are shown in Figure 6. The readings ranged from 2230 to $11745 \mathrm{ft} / \mathrm{s}(680$ to $3580 \mathrm{~m} / \mathrm{s})$ with an average velocity of approximately $7076 \mathrm{ft} / \mathrm{s}(2157 \mathrm{~m} / \mathrm{s})$. The general qualitative condition of the concrete members tested was considered "poor" to "very poor" (Whitehurst 1966).

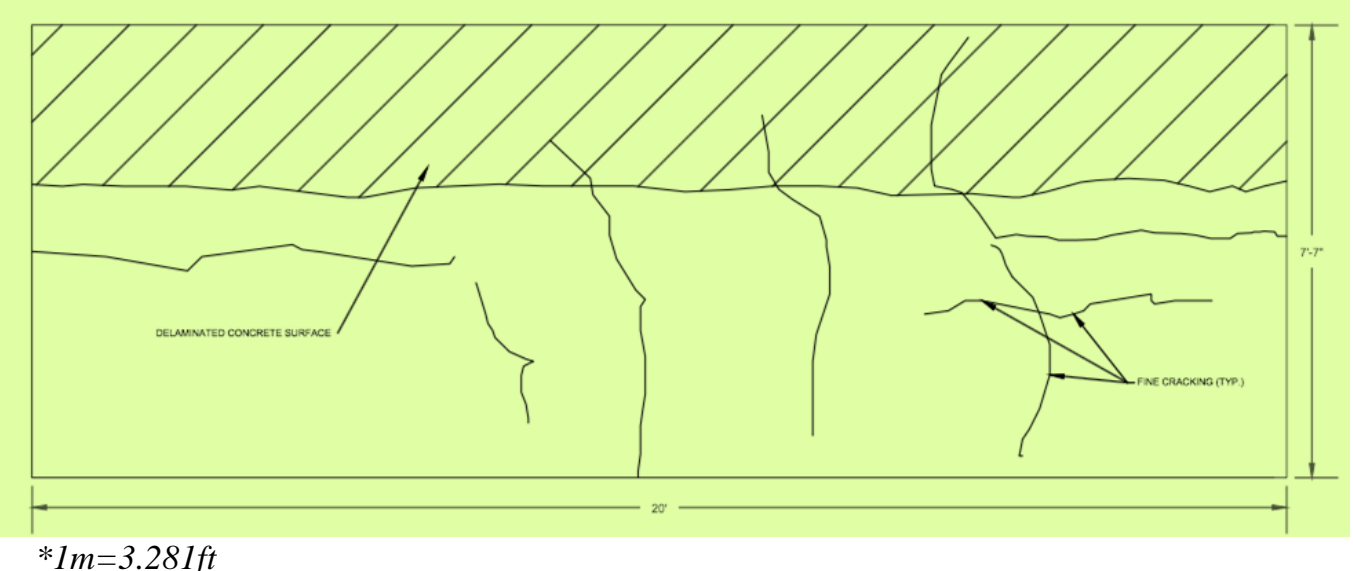

Figure 5: Deterioration map of a part of the wall 


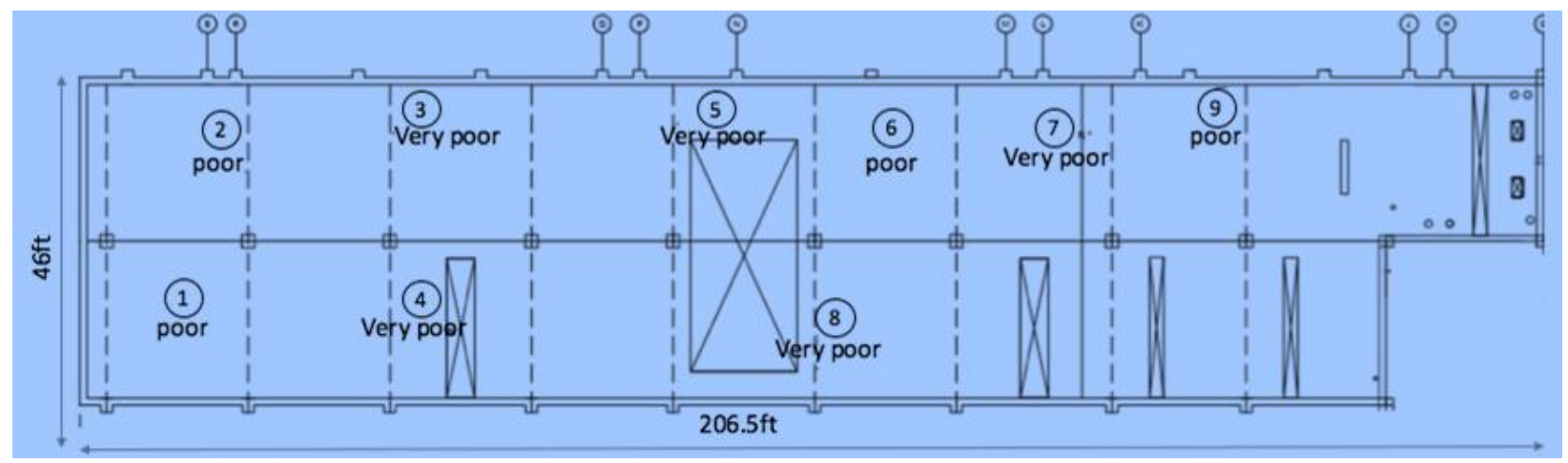

$* 1 m=3.281 f t$

Figure 6. UPV test locations and qualitative results

\section{Deterioration of Concrete Surface by Sulfate Attack}

Erosion is the deterioration of the concrete surface by different agents such as chemicals, weather, and abrasion. Erosion is most common when aggressive chemicals run on walls, drawing off the cementitious matrix, and leaving the harder coarse aggregate in place. Visual observation showed that the erosion depth typically varied between 1 to 2 inches $(25.4$ to $50.8 \mathrm{~mm}$ ), peak-to-valley. It is believed that sulfate attack is the primary deterioration mechanism in regions of surface erosion. In hardened concrete, calcium aluminate hydrate can react with a sulfate salt from outside the concrete producing calcium sulfoaluminate, formed within the framework of the hydrated cement paste.

\section{Laboratory Investigations and Results}

A total of six (6) partial-depth concrete core specimens were collected from the sulfur pit wall elements and six (6) full penetration depth cores were obtained from the roof slab using electric-powered waterlubricated, rotary diamond core drilling techniques. The concrete alkalinity $(\mathrm{pH})$, compressive strength (in accordance with ASTM C-42, chloride ion $\left(\mathrm{Cl}^{-}\right)$content, sulfate (SO4--) content and cement content were obtained from the extracted cores. A typical extracted core is shown in Figure 7.

The sidewall surfaces of the holes after extraction of the full-depth roof slab concrete cores clearly showed the delamination along roof slab top and soffit, approximately 3 to 4 inches (76.2 to $101.6 \mathrm{~mm}$ ) inward from each formed concrete surface. They were directly related to the embedded metal corrosion. Five (5) of six (6) core specimens extracted from the interior sulfur pit wall elements met laboratory testing criteria and were tested for compressive strength. The compressive strength of concrete ranged between $4234 \mathrm{psi}(29.2 \mathrm{MPa}$ ) to $7589 \mathrm{psi}(52.3 \mathrm{MPa})$. According to original design information, the tested cores were well above the minimum strength requirement of $3500 \mathrm{psi}$ (24.1MPa). The strength of concrete is therefore not an issue in this structure.
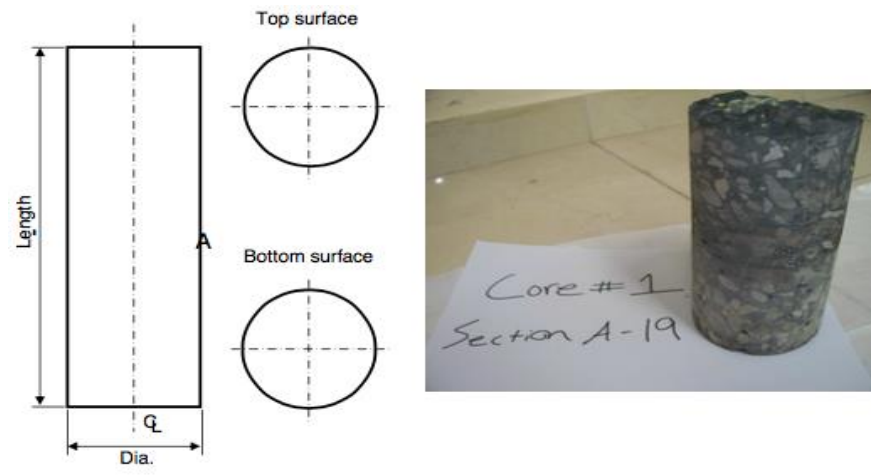

Figure 7. Concrete core obtained from the sulfur pit 
The concrete core samples extracted from the interior walls of the pit were profiled at three powdersampling depths per core, resulting in fifteen (15) powder samples, tested for chloride ion content. The chloride ion $\left(\mathrm{Cl}^{-}\right)$content by weight of cement ranged from $0.06 \%$ to $0.17 \%$. ACI [ACI 318 2008] limit chloride content contributed from the concrete ingredients to $0.1 \%$ for concrete in wet service. Threshold for corrosion initiation depends not only on chloride, but also on the available hydroxyl ion $\left(\mathrm{OH}^{-}\right)$. Threshold value of $0.4 \% \mathrm{Cl}^{-}$by mass of cement proposed by [CEB 1992] and 0.6 to $0.9 \mathrm{~kg} / \mathrm{m}^{3}$ typically used in the United States per [ACI 222.0R 2010]. Test results indicated low chloride ion contents in the samples when compared to total cement contents as determined by chemical testing. The chloride ion content test results reveal that chloride contents do not appear to be a significant contributor to the observed corrosion and distress manifestations.

Fifteen (15) powder samples obtained from the walls were tested for sulfate content. Sulfate (SO4--) content by weight of concrete ranged from $0.609 \%$ to $6.312 \%$. Test results indicated high sulfate contents when compared to total cement contents as determined by chemical testing. As such, sulfate content test results reveal that sulfate attack appear to be a significant contributor to the observed distress manifestations in the form of erosion and concrete cross-sectional losses. The sulfur pit was specified to incorporate high sulfate resistant Portland Cement (Type V), therefore the frequency and overall severity of erosion damage is minimal in the sulfur pit.

A pH color indicating solution (Phenolthalien) was used to measure the state of concrete alkalinity and the effect of exposure to sulfuric acid. The test revealed a significant loss of alkalinity extending from $11 \mathrm{~mm}$ to the full length of the core specimen. Evidence of low $\mathrm{pH}$ (more acidic) value appeared to be present on all tested concrete core samples. The lower $\mathrm{pH}$ value is an indicator of "depassivation" in the alkaline environment of concrete. All tested cores showed $\mathrm{pH}$ values less than 10 . The low concrete alkalinity can be considered a significant contributor to the corrosion processes observed at the subject sulfur pit.

\section{FINITE ELEMENT ANALYSIS OF SULFUR PIT}

Finite element modeling of the sulfur pit was conducted to investigate the stresses due to shrinkage and thermal loadings on the walls and the roof of the structural element. A 3D model of the sulfur pit was developed using the commercial software SAP2000 (Figure 8). The sulfur pit is $206.5 \mathrm{ft}(62.94 \mathrm{~m})$ long, $46 \mathrm{ft}(14 \mathrm{~m})$ wide, with a height of $7.7 \mathrm{ft}(2.34 \mathrm{~m})$. The columns were modeled as a line element and the walls, base slab and roof slab were modeled as a thick plate element. Applied loading includes the selfweight of the structure, shrinkage loading, and a thermal differential loading of $120^{\circ} \mathrm{C}$. The temperature of the molten sulfur is about $150{ }^{\circ} \mathrm{C}$ and the ambient environmental temperature and the temperature of the surrounding soil were considered as $30^{\circ} \mathrm{C}$. The thermal differential loading is applied to the walls and the roof slab of the sulfur storage tank.

Figure 9 shows the stresses in the roof slab and walls of the sulfur pit. The analysis shows that the subterranean sulfur pits are subjected to tensile stresses soon after construction. Tensile stresses in the walls results in the development of cracks even before the tanks are loaded with molten sulfur. These cracks develop from the bottom of the walls propagating up to the mid height of the walls. When the sulfur pit under investigation is subjected to thermal gradient loading from molten sulfur at high temperature, very high tensile stresses are developed in the top slab and the walls of the sulfur pit. The tensile stresses on the soffit of the roof slab due to thermal gradient are very high. In the presence of high tensile stresses and associated cracking on the soffit of the roof slab, the corrosion of reinforcing steel from sulfur in vapor form in the presence of moisture and air takes place at an accelerated rate.

The roof slab of the sulfur pit under investigation was found to be in severe distress, with a portion of the roof slab collapsing due to the high tensile stresses at the soffit of the roof slab due to the thermal 
gradient. The finite element analysis also shows high tensile stresses in the interior surfaces of the walls of the sulfur pit. In the lower portion of the walls, due to lack of moisture and air, only cracking was observed there. However, the top portion of the walls of the pit shows extensive delamination due to corrosion of the reinforcing steel. High tensile stresses in the walls and the presence of moisture and air in the upper portion of the tank, facilitates rapid corrosion of steel.

The finite element analysis of the sulfur pit under consideration brings forth important aspects, explaining the causes of rapid deterioration of concrete in these tanks and decreasing the service life of these structures. For ensuring enhanced service life of these sulfur pits, it is important to select a structural system that would limit the high tensile stresses developed in these reinforced concrete subterranean pits.
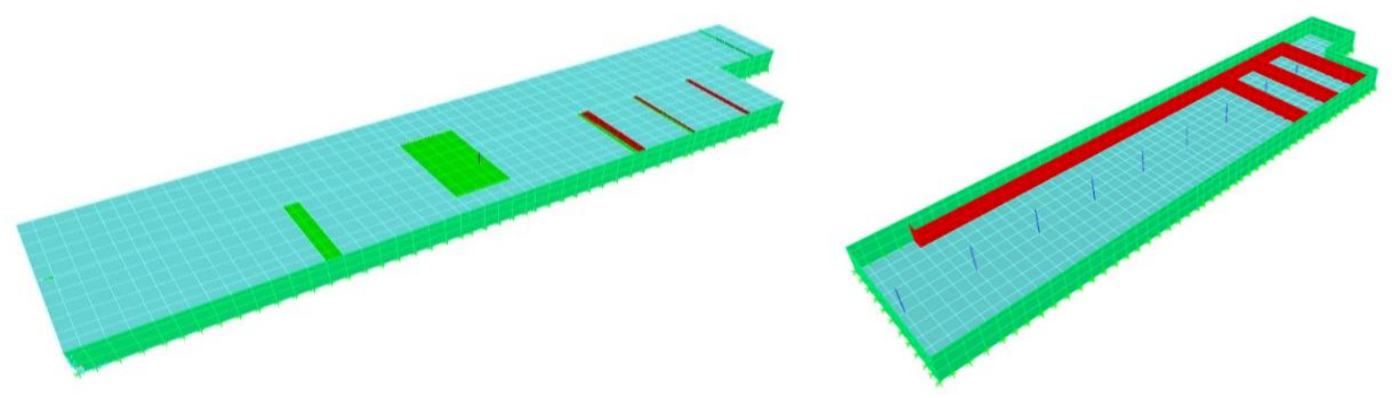

Figure 8. 3D view of the finite element model of the sulfur pit.

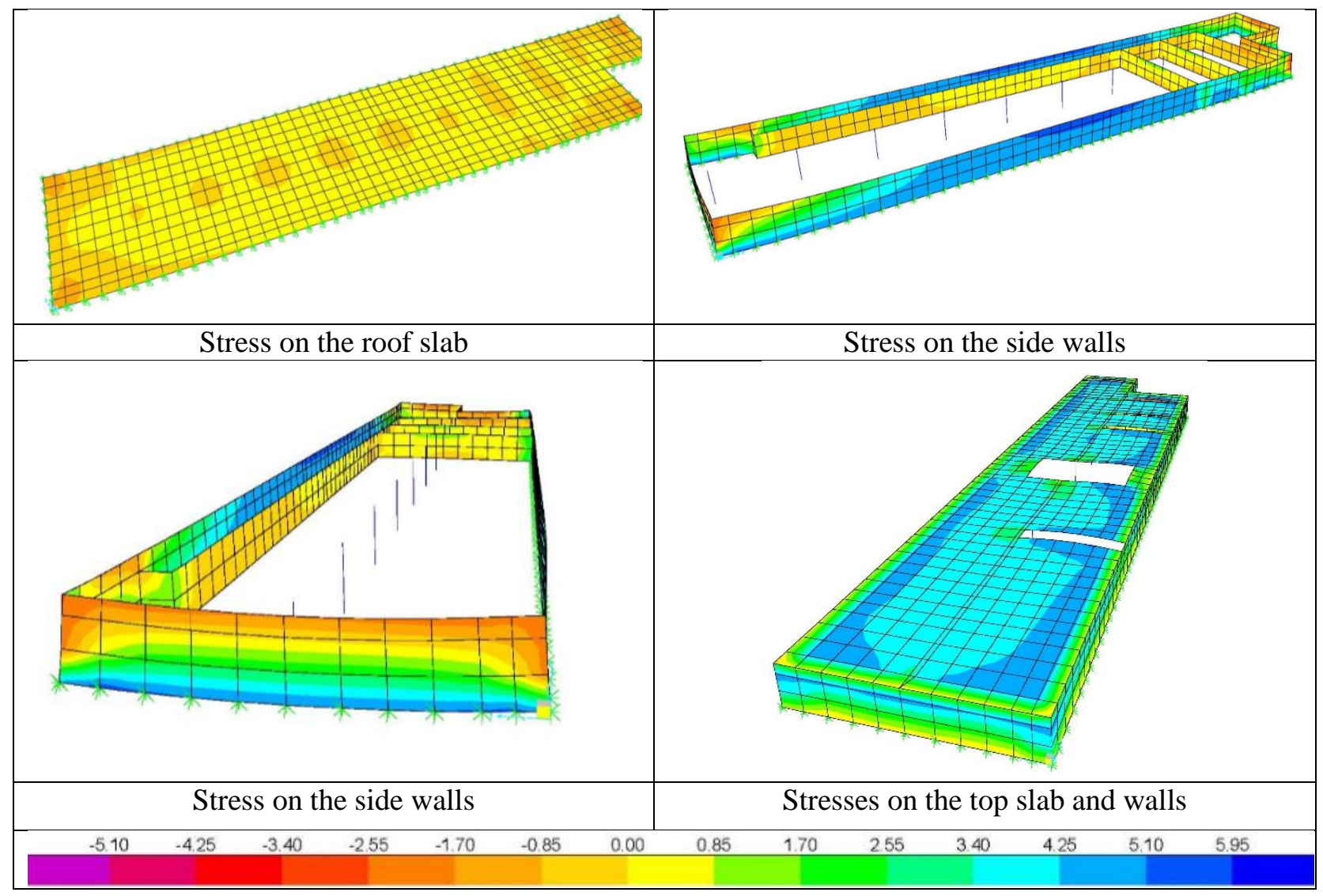

Figure 9. Stress contours from FE analysis for shrinkage and temperature gradient loading 


\section{CONCLUSION}

- The primary deterioration mechanism of the sulfur pit structure was corrosion of reinforcing steel, caused by the sulfuric acid reduces the concrete alkalinity and destroys the passivity protecting steel. This explains the fact that most of the corrosion-induced deterioration in sulfur pits takes place on the walls levels above molten sulfur level and the roof.

- The second deterioration mechanism is sulfate attack in regions of surface erosion. Calcium aluminate hydrate reacts with a sulfate salt from outside the concrete producing calcium sulfoaluminate, formed within the framework of the hydrate cement paste. Because of the increase in volume of the solid phase, concrete disintegrate gradually. Moreover, the baseexchange between calcium hydroxide and the sulfates, results in the formation of gypsum with an increase in volume of the solid phase.

- Although Type V cement is generally specified for use in concrete exposed to sulfate environment, it is considered less resistant to corrosion (less C3A content) and therefore increases the potential of concrete deterioration due to reinforcement corrosion in sulfur pits. Utilization of low permeability concrete with low w/c ration using Type-I cement and supplementary cement material (such as silica fume) could be the mitigation strategy to reduce both corrosion as well as sulfate attack in the sulfur pit concrete structure. Field experience has shown that use of Type-I cement with silica fume reduces the concrete permeability significantly and make it more resistant to both corrosion as well as to sulfate attacks.

- Cracking due to shrinkage and temperature loads allowed the ingress of sulfate/sulfuric acid to the concrete and further accelerated the deterioration.

- Use of a refractory potassium silicate liner to reduce temperature deferential and use of appropriate joints both eliminates cracking in the sulfur pit structure which slow down the ingress of the chemicals and therefore extend the structure service life.

\section{ACKNOWLEDGEMENTS}

The support provided by the Consulting Services Department, Saudi Aramco, Research Institute at King Fahd University of Petroleum and Minerals at Dhahran, Saudi Arabia and Structural Preservation Systems, Middle East (SPSME), in association with Inspectech, a subsidiary of Kabbani Construction Group are gratefully acknowledged. The support provided by Engr. Tariq Quereshi of AlYamama Contracting, for developing the model of the sulfur pit is acknowledged.

\section{REFERENCES}

Drimalas, T. (2007). "Laboratory and Field Evaluation of External Sulfate Attack." Phd Thesis, University of Texas at Austin, Austin, TX.

Folliard, K.J. and Sandberg, P. (1994)."Mechanisms of Concrete Deterioration by Sodium Sulfate Crystallization," Proceedings of Third International ACI/CANMET Conference on Concrete Durability, Nice, France, 933-945.

ACI Committee 201. (2008). "Guide to Durable Concrete (ACI 201.2R-08)." American Concrete Institute, Farmington Hills, MI, 49 Pages.

N.I. Dowling (1992). "Corrosion of Materials Used in Storage and Handling of Solid Elemental Sulphur", Proceeding of the International Symposium on Materials Performance: Sulphur and Energy, 31st Annual Conference of Metallurgists of CIM, Edmonton, 103-115. 
Khatri, R.P, Sirivivatnanon V. and Yang J.L. (1997). "Role of Permeability in Sulfate Attack," Cement and Concrete Research. Vol. 27 No. 8, 1179-1189.

ASTMC-597. "Standard Test Method for Pulse Velocity Through Concrete." ASTM International, West Conshohocken, PA, 4 Pages.

ASTM C-805. "Standard Test Method for Rebound Number of Hardened Concrete." ASTM International, West Conshohocken, PA, 4 Pages.

ASTM C-1383. "Standard Test Method for Measuring the P-Wave Speed and the Thickness of Concrete Plates Using the Impact-Echo Method." ASTM International, West Conshohocken, PA, 11 Pages.

ASTM C-876. "Standard Test Method for Corrosion Potentials of Uncoated Reinforcing Steel in Concrete." ASTM International, West Conshohocken, PA, 8 Pages.

Whitehurst E.A. (1996). "Evaluation of Concrete Properties from Sonic Tests", ACI Monograph No. 2, ACT, Detroit (Michigan, USA), 94 Pages.

ASTM C-42. "Standard Test Method for Obtaining and Testing Drilled Cores and Sawed Beams of Concrete." ASTM International, West Conshohocken, PA, 7 Pages.

ACI Committee 318 (2008). "Building Code Requirements for Structural Concrete and Commentary (ACI 318-08)." American Concrete Institute, Farmington Hills, MI, 473 Pages.

CEB Design Guide for Durable Concrete Structures, 2nd Edition, 1992, Thomas Telford Publishers.

ACI Committee 222.0R (2010). "Protection of Metals in Concrete Against Corrosion (ACI222.0R)." American Concrete Institute, Farmington Hills, MI, 41 Pages. 